\title{
Changes in Fetal Circulation After Maternal Corticosteroid Administration: A Systematic Review
}

\author{
Sanaz Mousavi $^{\circledR}$, Simin Taghavi ${ }^{1}$, Fatemeh Abbasalizadeh ${ }^{1}$, Shabnam Vazifekhah ${ }^{2 *}{ }^{\circledR}$, Mohammad \\ Naghavi-Behzad ${ }^{3}$
}

\begin{abstract}
Objectives: The present study aimed at reviewing the existing literature on the effects of maternal corticosteroid administration on pulsatility index (PI) values in the umbilical artery and middle cerebral artery (MCA).

Materials and Methods: The search for relevant materials on "evaluating the effect of corticosteroids on fetal circulation" included the following databases: PubMed, Scopus, Cochrane Library, ISI Web of Science, Proquest, Google Scholar, EMBASE, and Iranian Databases of Magiran, Iran Medex, Barakat knowledge network system, Scientific Information Database, Iranian Research Institute for Information Science and Technology, from 1990 to June 2017.

Results: In our search for the relevant literature, 19 articles were found. In total, these studies included 654 pregnant women, who were evaluated for fetal circulation before and after corticosteroid (betamethasone or dexamethasone) injection, for PI values in the umbilical artery and MCA. The effects of steroid injection were evaluated between 23 and 34 weeks of gestation.

Conclusions: Overall, the results of the reviewed studies indicated that antenatal exposure to corticosteroids reduces umbilical artery PI and MCA PI and improves fetal circulation during pregnancy.

Keywords: Antenatal corticosteroids, Pregnancy, Umbilical artery pulsatility index, Middle cerebral artery pulsatility index
\end{abstract}

\section{Introduction}

Corticosteroids have been used extensively to accelerate fetal lung maturation in premature birth (1). Prematurity is known to cause neonatal morbidity and mortality, and corticosteroids are effective in lowering these complications (1). Maternal use of corticosteroids is known to be associated with fetal congenital adrenal hypoplasia, and also some other maternal complications (2-4). In the setting of preterm delivery, corticosteroids are administrated to enhance fetal lung maturation (3). When there is a risk for preterm delivery, two-dose courses of synthetic corticosteroids (betamethasone, dexamethasone) are administered routinely, to prevent prematurity complications such as respiratory distress syndrome, and intraventricular hemorrhage and also to reduce neonatal death $(5,6)$. While in some studies, serious side effects of steroid administration have not been verified, there are concerns about the repeated or prolonged antenatal exposure to corticosteroids (7). Indeed some other studies have shown that use of corticosteroids can cause a reduction in fetal movement, fetal breathing, fetal heart rate variability, and biophysical profile score (1). Taken together, there are conflicting data if corticosteroids change fetal hemodynamics. Some studies have revealed that following the corticosteroid administration, there is a return of diastolic flow in growth-restricted fetuses with absent/reversed end diastolic flow in the umbilical artery $(8,9)$.

In addition to the effects of glucocorticoids on the lung maturity, many extra-pulmonary functions have been attributed to these steroids. It has been known that the prenatal glucocorticoid administration to mother or fetus induces fetal vasoconstriction $(10,11)$, and it may cause increased peripheral vascular resistance and hypertension $(11,12)$. Some other studies also report the increase of fetal cerebral flow after corticosteroid administration (13). The two routinely-administered glucocorticoids to pregnant women, which are not known to bind to plasma proteins, are betamethasone and dexamethasone. Their concentrations in the fetus plasma are relatively high given their minimal metabolism by the placenta during 2-3 hours after administration (14). Particularly, the fetal brain is known to be susceptible to the high concentration of glucocorticoid, and it can increase fetal brain vascular resistance, leading to a decrease in cerebral blood flow (15). In addition, there are reports on the reduction of neuronal cell number in the fetal brain after in utero exposure of primates to corticosteroids (16).

A study by Niroomanesh et al indicated that all of 40 fetuses, exposed to betamethasone, had a decreased 
umbilical artery pulsatility index (PI) and improvement in fetal perfusion (17). On the contrary, Deren et al reported no change in the umbilical and middle cerebral artery (MCA) perfusion after betamethasone administration to mother (18). The purpose of this review was to provide an overview of the reported effects of corticosteroids on fetal circulation.

\section{Methods and Materials}

The following databases were searched for articles related to "evaluating the effect of corticosteroids on fetal circulation" from 1990 to June 2017: PubMed, Scopus, Cochrane library, ISI Web of Science, Proquest, Google scholar and EMBASE, Iranian databases of Magiran, Iran Medex, Barakat knowledge network system, Scientific Information Database, Iranian Research Institute for Information Science and Technology. The searched keywords were: "preterm delivery AND betamethasone OR dexamethasone OR fetal corticosteroid therapy" AND "fetal circulation OR fetal Umbilical artery Doppler OR fetal Middle cerebral artery Doppler OR Ductus venosus Doppler OR fetal behavior OR Uterine artery Doppler".

Thus articles either in Persian or English which were published from 1990 until June 2017 and were related to "evaluating the effect of corticosteroids (betamethasone or dexamethasone) on fetal circulation" were included in our review. Articles in other languages, those with poor quality, organization reports, and letters to editors, as well as conference abstracts and theses were excluded from the review.

Data Extraction and Quality Assessment

We evaluated all of the relevant articles retrieved by keywords' search, and excluded incompatible or irrelevant articles. The selected articles were evaluated for potential risk of bias by two different reviewers and controversies were referred to a third reviewer. The extracted data were summarized in the extraction forms, as follows: first authors' name, date of publication, country in which study had been done, design of study, type of drug, gestational age, fetal circulation before corticosteroid injection, umbilical artery PI after corticosteroid injection, MCA PI after corticosteroid injection, Ductus venosus PI after corticosteroid injection, and uterine artery PI.

The Search Result and Study Characteristics

The search in the above-mentioned databases resulted in the retrieval of 678 articles, from which 294 were duplicates. Following precise evaluation of the articles and removal of non-full-text abstracts, the number of papers reduced to 29 papers. Furthermore, 10 studies were excluded due to lack of access to the full text. Therefore, the articles included in this systematic review were 19 fulltext articles. A flow chart of literature retrieval is shown in Figure 1.

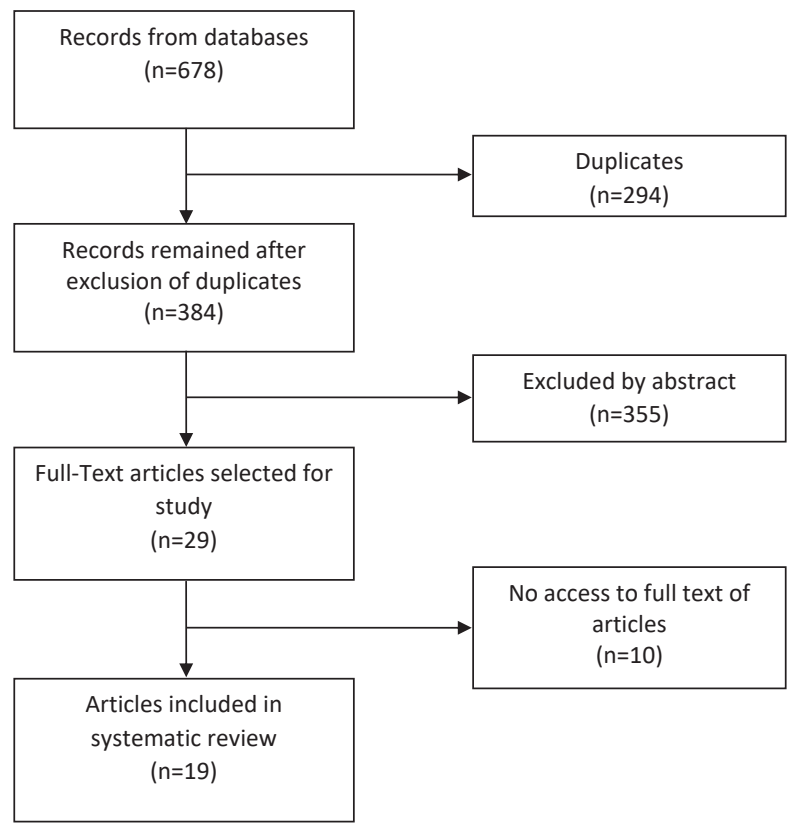

Figure 1. Flow Chart of Literature Retrieval.

\section{Participant Characteristics}

In total, 654 pregnant women were evaluated for fetal circulation (umbilical artery PI, and MCA PI) before and after betamethasone or dexamethasone injection. The effects of steroids were evaluated between 23 and 34 weeks of gestation.

\section{Statistical Analysis}

Heterogeneity was determined using the Cochran's $Q$ test and $I^{2}$. A significance level of $P<0.10$ for Cochran's $Q$ test, or $\mathrm{I}^{2}>50 \%$ was considered as a clinically important heterogeneity (19). Publication bias was assessed graphically using a funnel plot and mathematically using an adjusted rank correlation test, according to Begg and Mazumdar rank correlation and Egger test. The number of fetuses with reduced biophysical profile test, by betamethasone or dexamethasone injection, was used to obtain the event rate.

\section{Results}

The random effects model was used to identify the statistical heterogeneity (Table 1). The forest plot is shown in Figure 2. The heterogeneity results indicated the total umbilical artery PI $(0.09 \%, 95 \% \mathrm{CI}=0.02$ to $0.35, P=0.001)$, total MCA PI $(0.09 \%, 95 \% \mathrm{CI}=0.026$ to $0.35, P=0.001)$, the umbilical artery PI in the group with normal circulation before steroid injection $(0.06 \%, 95 \%$ $\mathrm{CI}=0.01$ to $0.040, P=0.003$ ), and MCA PI in the group with normal circulation before steroid injection $(0.06 \%$, $95 \% \mathrm{CI}=0.01$ to $0.40, P=0.003$ ) (Tables 2 amd 3).

The meta-analysis of the results of corticosteroid effects on umbilical artery PI is demonstrated in Figure 2.

The meta-analysis of results of corticosteroid effects on 
Table 1. Heterogeneity Results for Umbilical Artery PI and MCA PI

\begin{tabular}{|c|c|c|c|c|c|c|c|c|}
\hline & Fetal Circulation & $n$ & Point Estimation & $95 \% \mathrm{Cl}$ & $d f$ & $Q$ & $1^{2}$ & $P$ Value \\
\hline \multirow{3}{*}{ Umbilical artery PI } & Abnormal & 6 & 0.521 & $(0.115-2.357)$ & 5 & 30.94 & 83.84 & 0.397 \\
\hline & Normal & 12 & 0.063 & $(0.010-0.402)$ & 11 & 57.82 & 80.98 & 0.003 \\
\hline & Total & 20 & 0.097 & $(0.026-0.354)$ & 19 & 156.61 & 87.87 & $<0.001$ \\
\hline \multirow{3}{*}{ MCA PI } & Abnormal & 6 & 0.521 & $(0.115-2.357)$ & 5 & 30.94 & 83.84 & 0.397 \\
\hline & Normal & 12 & 0.063 & $(0.010-0.402)$ & 11 & 57.82 & 80.98 & 0.003 \\
\hline & Total & 20 & 0.097 & $(0.026-0.354)$ & 19 & 156.61 & 87.87 & $<0.001$ \\
\hline
\end{tabular}

MCA PI was demonstrated in Figure 3.

\section{Discussion}

Serious side effects have not been reported for fetal in utero exposure to corticosteroids; however, there are data about the effects of steroids on fetal behavior and circulation. In the present review, we aimed to systematically evaluate the effect of maternal corticosteroid administration on the alterations of fetal circulation. Our systematic review showed that after fetal exposure to corticosteroids, umbilical artery PI and MCA PI decrease and that in pregnancies receiving corticosteroids, there is improvement in fetal circulation.

Administration of betamethasone (synthetic glucocorticoid) to the mother at risk of preterm delivery would lead to transient return of end diastolic flow in the umbilical artery (20), and similar changes in other fetal vascular beds (21). These changes indicate that betamethasone has potentially important cardiovascular effects (20). In human fetuses, antenatal administration of betamethasone in the fetuses with absent end diastolic flow in the umbilical artery results in a transient return of end-diastolic flow in about two thirds of pregnancies (9). Decrease in the MCA PI following the return of end-

Umbilical Artery PI

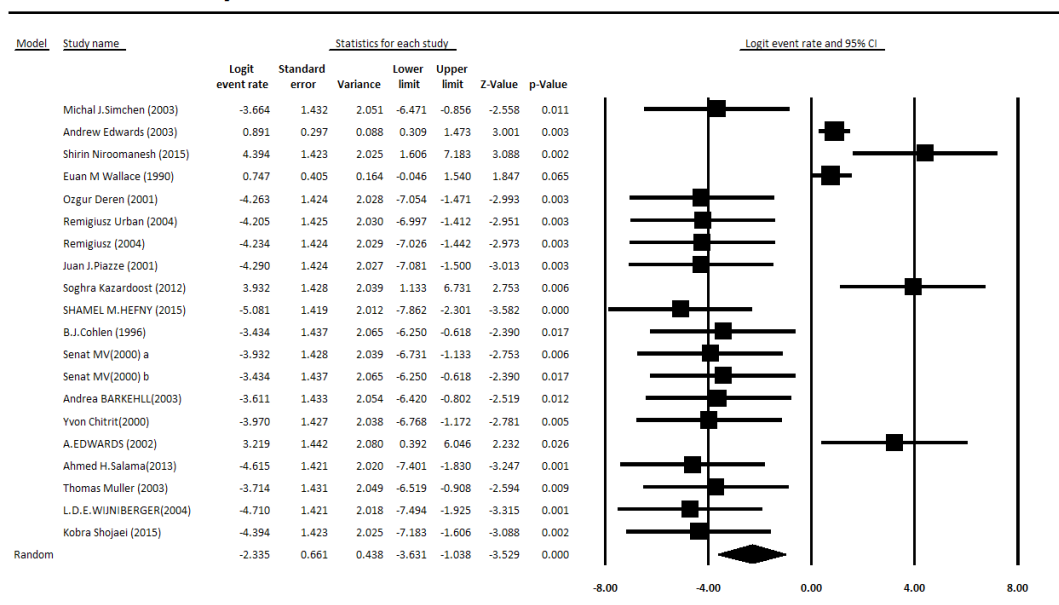

Figure 2. Meta-analysis of Results of Corticosteroid Effects on Umbilical Artery PI.

\section{MCA PI}

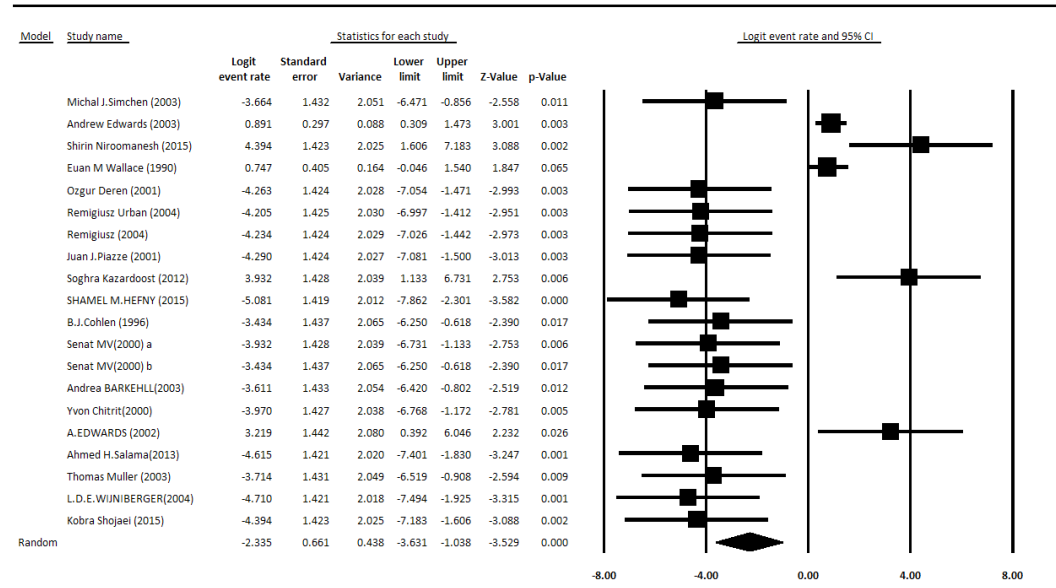

Figure 3. Meta-analysis of Results of Corticosteroid Effects on MCA PI. 
Table 2. Detailed Review of the Literature Based on Time of Study, Country, Design of Study, Gestational Age, and Sample Size

\begin{tabular}{|c|c|c|c|c|c|c|}
\hline First Author & Year & Country & Design of study & Type of drug & Gestational age (wk) & Sample size \\
\hline Simchen & 2003 & Canada & Prospective & Betamethasone (12 $\mathrm{mg} \times 2, \mathrm{IM}, 24 \mathrm{~h})$ & $24-34$ & 19 \\
\hline Edwards & 2003 & Australia & Retrospective & Betamethasone (11/4 mg ×2, IM, 24h) & $23-33$ & 55 \\
\hline Niroomanesh & 2015 & Iran & Prospective & Betamethasone (12 $\mathrm{mg} \times 2, \mathrm{IM}, 24 \mathrm{~h})$ & $24-34$ & 40 \\
\hline Wallace & 1990 & Australia & Retrospective & Betamethasone $(11 / 4 \mathrm{mg} \times 2, \mathrm{IM}, 24 \mathrm{~h})$ & $23-33$ & 28 \\
\hline Deren & 2001 & USA & Prospective & Betamethasone (12 mg ×2, IM, $24 \mathrm{~h}$ ) & $28-34$ & 35 \\
\hline Urban & 2004 & Poland & Prospective & Betamethasone (12 mg ×2, IM, $24 \mathrm{~h}$ ) & $31 / 5$ & 33 \\
\hline Remigiusz & 2004 & Poland & Prospective & Dexamethasone (6 $\mathrm{mg} \times 4$, IM, $12 \mathrm{~h}$ ) & $31 / 4$ & 34 \\
\hline Piazze & 2001 & Italy & Prospective & Betamethasone (12 mg $\times 2, \mathrm{IM}, 24 \mathrm{~h})$ & $30 / 7$ & 36 \\
\hline Kazardoost & 2012 & Iran & Prospective & Betamethasone (12 $\mathrm{mg} \times 2$, IM, 24h) & $26-34$ & 25 \\
\hline Hefny & 2015 & $\mathrm{NR}^{*}$ & Prospective & Dexamethasone (6 mg × 4, IM, $12 \mathrm{~h}$ ) & $28-34$ & 80 \\
\hline Cohlen & 1996 & Netherlands & Prospective & Betamethasone (12 $\mathrm{mg} \times 2, \mathrm{IM}, 24 \mathrm{~h}$ ) & $26-32$ & 15 \\
\hline Senat & 2000 & France & Prospective & Betamethasone (12 mg × 2,IM,24 h) & & 25 \\
\hline Senat & 2000 & France & Prospective & Dexamethasone (6 mg × 4, IM, $12 \mathrm{~h}$ ) & & 15 \\
\hline Barkehll & 2003 & Australia & Prospective & Betamethasone $(11 / 4 \mathrm{mg} \times 2, \mathrm{IM}, 24 \mathrm{~h})$ & $24-34$ & 18 \\
\hline Chitrit & 2000 & France & Cross sectional & Dexamethasone, (4 mg × 6, IV, 8 h) & $26-33$ & 26 \\
\hline Edwards & 2002 & Australia & Prospective & Betamethasone $(11 / 4 \mathrm{mg} \times 2, \mathrm{IM}, 24 \mathrm{~h})$ & $28 / 5$ & 12 \\
\hline Salama & 2013 & Egypt & Prospective & Dexamethasone ( $24 \mathrm{mg} \times 3, \mathrm{IM}, 8 \mathrm{~h}$ ) & $31 / 9$ & 50 \\
\hline Muller & 2003 & Germany & Retrospective & $\begin{array}{l}\text { Betamethasone ( } 8 \mathrm{mg} / \text { or Dexamethasone } \\
12 \mathrm{mg} \text {, single dose) }\end{array}$ & & 20 \\
\hline Thuring & 2011 & Sweden & Prospective & Betamethasone, (12 mg ×2, IM, 24 h) & $23-33$ & 33 \\
\hline Wijniberger & 2004 & Germany & Prospective & Betamethasone (12 mg ×2, IM, 24 h) & $24-34$ & 55 \\
\hline Shojaei & 2015 & Iran & Prospective & Betamethasone, (12 mg × 2, IM, 24 h) & $24-34$ & 40 \\
\hline
\end{tabular}

* NR: Not reported.

diastolic flow in the umbilical artery suggests widespread vasodilatation (21). The vascular function is regulated by glucocorticoids, and fetal cardiovascular parameters which could be altered by synthetic glucocorticoids, such as betamethasone (15).

Studies have shown that changes in blood flow due to post-steroid injection are transient effects $(9,22)$. The lack of significant prolongation in pregnancies with improvement in circulation supports this idea that these changes in fetal circulation do not alter pregnancy outcome, and do not lead to the improvement in fetal condition (9). Several mechanisms have been suggested for vasodilatory effects of corticosteroids on fetal circulation. One mechanism is the up-regulation and increased secretion of placental corticotropin-releasing-hormone, which is mediated by nitric oxide $(13,22)$.

Decreased MCA PI, following corticosteroid administration, shows a redistribution of blood to the fetal cerebral circulation (13,21-23). There are glucocorticoid receptors in the fetal brain, and a number of corticosteroid receptors in brainstem nuclei, which are known to control fetal sleep and activity (24). The effect of corticosteroid on fetal blood pressure may be another mechanism for alteration of fetal cerebral flow (10). Since corticosteroid exposure alters cardiotocogram patterns and biophysical profile parameters, Doppler study is the only reliable tool for the diagnosis of fetal compromise in pregnancies receiving antenatal corticosteroids $(22,25,26)$.

Niroomanesh et al reported that in all of the 40 fetuses, exposure to betamethasone decreased umbilical artery PI and led to the improvement in fetal perfusion (17). On the contrary, Deren et al reported no change in umbilical and MCA perfusion after maternal betamethasone administration (18). Researchers have indicated that betamethasone and dexamethasone have no effect on Doppler indices in umbilical arteries, descending aorta and MCA, in growth-restricted fetuses (27). Evaluation of the effects of dexamethasone administration on fetal Doppler flow velocity demonstrated that there was no significant changes in umbilical artery PI and MCA PI (26). It was reported that the administration of betamethasone to mother with absent end diastolic flow in the umbilical 
Table 3. Effects of Maternal Betamethasone and Dexamethasone Administration on Umbilical Artery PI, MCA PI, DV PI and Uterine Artery PI (as Reported in the Literature)

\begin{tabular}{|c|c|c|c|c|c|c|c|c|}
\hline \multirow{2}{*}{ First Author } & \multirow{2}{*}{$\begin{array}{l}\text { Design of } \\
\text { Study }\end{array}$} & \multirow{2}{*}{ Type of Drug } & \multirow{2}{*}{$\begin{array}{l}\text { Gestational } \\
\text { age (wk) }\end{array}$} & \multirow{2}{*}{$\begin{array}{l}\text { Before corticosteroid } \\
\text { injection }\end{array}$} & \multicolumn{3}{|c|}{ After Corticosteroid Injection } & \multirow{2}{*}{$\begin{array}{l}\text { Uterine } \\
\text { Artery PI }\end{array}$} \\
\hline & & & & & $\begin{array}{l}\text { Umbilical } \\
\text { artery PI }\end{array}$ & MCA PI & DV PI & \\
\hline Simchen & Prospective & $\begin{array}{l}\text { Betamethasone }(12 \mathrm{mg} \times 2 \text {, } \\
\mathrm{IM}, 24 \mathrm{~h})\end{array}$ & $24-34$ & ARED & 0 & 0 & NR & NR \\
\hline Edwards & Retrospective & $\begin{array}{l}\text { Betamethasone }(11 / 4 \mathrm{mg} \times 2 \text {, } \\
\mathrm{IM}, 24 \mathrm{~h})\end{array}$ & $23-33$ & AEDF & 39 & 0 & NR & NR \\
\hline Niroomanesh & Prospective & $\begin{array}{l}\text { Betamethasone (12 } \mathrm{mg} \times 2 \text {, } \\
\mathrm{IM}, 24 \mathrm{~h})\end{array}$ & $24-34$ & Normal & 40 & 0 & NR & 40 \\
\hline Wallace & Retrospective & $\begin{array}{l}\text { Betamethasone }(11 / 4 \mathrm{mg} \times 2 \text {, } \\
\mathrm{IM}, 24 \mathrm{~h})\end{array}$ & $23-33$ & AEDF & 19 & NR & NR & NR \\
\hline Deren & Prospective & $\begin{array}{l}\text { Betamethasone (12 } \mathrm{mg} \times 2 \text {, } \\
\mathrm{IM}, 24 \mathrm{~h})\end{array}$ & $28-34$ & Normal & 0 & 0 & NR & NR \\
\hline Urban & Prospective & $\begin{array}{l}\text { Betamethasone (12 } \mathrm{mg} \times 2 \text {, } \\
\mathrm{IM}, 24 \mathrm{~h})\end{array}$ & $31 / 5$ & Normal & 0 & 0 & NR & NR \\
\hline Remigiusz & Prospective & $\begin{array}{l}\text { Dexamethasone }(6 \mathrm{mg} \times 4 \text {, } \\
\mathrm{IM}, 12 \mathrm{~h})\end{array}$ & $31 / 4$ & Normal & 0 & 34 & NR & NR \\
\hline Piazze & Prospective & $\begin{array}{l}\text { Betamethasone }(12 \mathrm{mg} \times 2 \text {, } \\
\mathrm{IM}, 24 \mathrm{~h})\end{array}$ & $30 / 7$ & Normal & 0 & 21 & NR & NR \\
\hline Kazardoost & Prospective & $\begin{array}{l}\text { Betamethasone (12 } \mathrm{mg} \times 2 \text {, } \\
\mathrm{IM}, 24 \mathrm{~h})\end{array}$ & $26-34$ & Normal & 25 & 0 & NR & NR \\
\hline Hefny & Prospective & $\begin{array}{l}\text { Dexamethasone }(6 \mathrm{mg} \times 4 \text {, } \\
\mathrm{IM}, 12 \mathrm{~h} \text { ) }\end{array}$ & $28-34$ & Normal & 0 & 0 & NR & NR \\
\hline Cohlen & Prospective & $\begin{array}{l}\text { Betamethasone }(12 \mathrm{mg} \times 2 \text {, } \\
\mathrm{IM}, 24 \mathrm{~h})\end{array}$ & $26-32$ & Normal & 0 & 0 & NR & 0 \\
\hline Senat & Prospective & $\begin{array}{l}\text { Betamethasone (12 } \mathrm{mg} \times \\
2, \mathrm{IM}, 24 \mathrm{~h})\end{array}$ & & Normal & 0 & 0 & NR & 0 \\
\hline Senat & Prospective & $\begin{array}{l}\text { Dexamethasone }(6 \mathrm{mg} \times 4 \text {, } \\
\mathrm{IM}, 12 \mathrm{~h})\end{array}$ & & Normal & 0 & 0 & NR & 0 \\
\hline Barkehll & Prospective & $\begin{array}{l}\text { Betamethasone }(11 / 4 \mathrm{mg} \times 2 \text {, } \\
\mathrm{IM}, 24 \mathrm{~h})\end{array}$ & $24-34$ & AEDF & 0 & NR & NR & NR \\
\hline Chitrit & $\begin{array}{l}\text { Cross } \\
\text { sectional }\end{array}$ & $\begin{array}{l}\text { Dexamethasone, ( } 4 \mathrm{mg} \times 6 \text {, } \\
\mathrm{IV}, 8 \mathrm{~h})\end{array}$ & $26-33$ & Normal & 0 & 26 & NR & NR \\
\hline Edwards & Prospective & $\begin{array}{l}\text { Betamethasone }(11 / 4 \mathrm{mg} \times 2 \text {, } \\
\mathrm{IM}, 24 \mathrm{~h})\end{array}$ & $28 / 5$ & AEDF & 12 & 12 & 0 & NR \\
\hline Salama & Prospective & $\begin{array}{l}\text { Dexamethasone }(24 \mathrm{mg} \times 3 \text {, } \\
\mathrm{IM}, 8 \mathrm{~h})\end{array}$ & $31 / 9$ & Normal & 0 & 50 & NR & 0 \\
\hline Muller & Retrospective & $\begin{array}{l}\text { Betamethasone ( } 8 \mathrm{mg} / \mathrm{or} \\
\text { Dexamethasone } 12 \mathrm{mg} \text {, single } \\
\text { dose) }\end{array}$ & & AREDV & 0 & 11 & 0 & NR \\
\hline Thuring & Prospective & $\begin{array}{l}\text { Betamethasone, }(12 \mathrm{mg} \times 2 \text {, } \\
\mathrm{IM}, 24 \mathrm{~h})\end{array}$ & $23-33$ & Normal/AREDF & NR & 0 & NR & 0 \\
\hline Wijniberger & Prospective & $\begin{array}{l}\text { Betamethasone (12 } \mathrm{mg} \times 2 \text {, } \\
\mathrm{IM}, 24 \mathrm{~h} \text { ) }\end{array}$ & $24-34$ & NR & 0 & 0 & 0 & NR \\
\hline Shojaei & Prospective & $\begin{array}{l}\text { Betamethasone, (12 } \mathrm{mg} \times 2 \text {, } \\
\mathrm{IM}, 24 \mathrm{~h})\end{array}$ & $24-34$ & NR & 0 & 0 & NR & 0 \\
\hline
\end{tabular}

NR: Not Reported; MCA PI: Middle cerebral artery pulsatility index; DV PI: Ductus venosus pulsatility index; ADEF: Absent end diastolic flow in umbilical artery; ARED: Absent/reversed end diastolic flow in umbilical artery.

artery leads to the transient return of end diastolic flow (28). Results of a study on 25 median age (19-42) women indicated that antenatal betamethasone administration decreases fetal movement, fetal biophysical profile, and umbilical artery indices while they are unable to show any effects on MCA Doppler indices (29). Administration of six weekly doses of dexamethasone (4 mg, IV injection) had no effects on the umbilical artery PI and MCA PI during days 2 and 7, and only, a significant decrease in MCA PI was reported on day 4 (25). Administration of two consecutive doses of betamethasone in 35 singleton pregnancies demonstrated that administration of the steroid did not affect Doppler indices including MCA and umbilical artery PIs, but transiently decreased biophysical 
profile scores (18). In another study, it was reported that the antenatal administration of betamethasone in pregnancies complicated by AEDF in the umbilical artery induced the return of end-diastolic flow in the umbilical artery as early as 4 hours (21). Antenatal corticosteroid therapy with betamethasone or dexamethasone leads to the return of positive end diastolic flow in the pregnancies with absent/reversed end diastolic flow in the umbilical arteries; however, there was no significant change in the umbilical artery PI, while there was an overall drop in MCA PI (13). In addition, it was reported that betamethasone therapy had no significant effect on the umbilical artery PI, while it significantly decreased MCA PI 48 hours after last administration of betamethasone. Then it returned to the pretreatment values, 96 hours after injection (22). Similar results have been reported on the effects of dexamethasone (23).

\section{Conclusions}

The results of our systematic showed that antenatal corticosteroid therapy reduces the umbilical artery PI and MCA PI. Our results also indicated that while corticosteroid therapy may improve fetal circulation transiently, it does not alter fetal outcome.

\section{Conflict of Interests}

Authors declare that they have no conflict of interests.

\section{Ethical Issues}

Not applicable.

\section{Financial Support}

None.

\section{References}

1. Brownfoot FC, Gagliardi DI, Bain E, Middleton P, Crowther CA. Different corticosteroids and regimens for accelerating fetal lung maturation for women at risk of preterm birth. Cochrane Database Syst Rev. 2013(8):Cd006764. doi:10.1002/14651858.CD006764.pub3

2. Trainer PJ. Corticosteroids and pregnancy. Semin Reprod Med. 2002;20(4):375-380. doi:10.1055/s-2002-36710

3. Eventov-Friedman S, Shinwell ES. Current controversies in perinatal steroid therapy. Acta Paediatr. 2008;97(11):14921501. doi:10.1111/j.1651-2227.2008.00907.x

4. McGee DC. Steroid use during pregnancy. J Perinat Neonatal Nurs. 2002;16(2):26-39.

5. Roberts D, Brown J, Medley N, Dalziel SR. Antenatal corticosteroids for accelerating fetal lung maturation for women at risk of preterm birth. Cochrane Database Syst Rev. 2017;3:Cd004454. doi:10.1002/14651858.CD004454. pub3

6. Crowley P, Chalmers I, Keirse MJ. The effects of corticosteroid administration before preterm delivery: an overview of the evidence from controlled trials. Br J Obstet Gynaecol. 1990;97(1):11-25.

7. Crowther CA, Harding JE. Repeat doses of prenatal corticosteroids for women at risk of preterm birth for preventing neonatal respiratory disease. Cochrane Database Syst Rev. 2007(3):Cd003935. doi:10.1002/14651858. CD003935.pub2.

8. Wallace EM, Baker LS. Effect of antenatal betamethasone administration on placental vascular resistance. Lancet. 1999;353(9162):1404-1407. doi:10.1016/s01406736(98)08229-4

9. Edwards A, Baker LS, Wallace EM. Changes in umbilical artery flow velocity waveforms following maternal administration of betamethasone. Placenta. 2003;24(1):1216.

10. Derks JB, Giussani DA, Jenkins SL, et al. A comparative study of cardiovascular, endocrine and behavioural effects of betamethasone and dexamethasone administration to fetal sheep. J Physiol. 1997;499(Pt 1):217-226.

11. Koenen SV, Mecenas CA, Smith GS, Jenkins S, Nathanielsz PW. Effects of maternal betamethasone administration on fetal and maternal blood pressure and heart rate in the baboon at 0.7 of gestation. Am J Obstet Gynecol. 2002;186(4):812-817.

12. Jellyman JK, Gardner DS, Fowden AL, Giussani DA. Effects of dexamethasone on the uterine and umbilical vascular beds during basal and hypoxemic conditions in sheep. Am J Obstet Gynecol. 2004;190(3):825-835. doi:10.1016/j. ajog.2003.09.046

13. Muller T, Nanan R, Dietl J. Effect of antenatal corticosteroid administration on Doppler flow velocity parameters in pregnancies with absent or reverse end-diastolic flow in the umbilical artery. Acta Obstet Gynecol Scand. 2003;82(9):794-796.

14. Ballard PL, Ballard RA. Scientific basis and therapeutic regimens for use of antenatal glucocorticoids. Am J Obstet Gynecol. 1995;173(1):254-262.

15. Miller SL, Chai M, Loose J, et al. The effects of maternal betamethasone administration on the intrauterine growthrestricted fetus. Endocrinology. 2007;148(3):1288-1295. doi:10.1210/en.2006-1058

16. Uno $\mathrm{H}$, Lohmiller $\mathrm{L}$, Thieme $\mathrm{C}$, et al. Brain damage induced by prenatal exposure to dexamethasone in fetal rhesus macaques. I. Hippocampus. Brain Res Dev Brain Res. 1990;53(2):157-167.

17. Niroomanesh S, Shojaei K, Moghadam SF, Mohammadi N, Rahimi Z, RezaeiKeyhanaei K. Effect of prenatal betamethasone on fetal, uteroplacental, and maternal blood flow velocity in pregnancies complicated by fetal growth restriction. Int J Gynaecol Obstet. 2015;130(3):270-273. doi:10.1016/j.ijgo.2015.04.043

18. Deren O, Karaer C, Onderoglu L, Yigit N, Durukan T, Bahado-Singh RO. The effect of steroids on the biophysical profile and Doppler indices of umbilical and middle cerebral arteries in healthy preterm fetuses. Eur J Obstet Gynecol Reprod Biol. 2001;99(1):72-76.

19. Higgins JP, Green S. Cochrane handbook for systematic reviews of interventionsJohn. John Wiley \& Sons; 2011.

20. Simchen MJ, Alkazaleh F, Adamson SL, et al. The fetal cardiovascular response to antenatal steroids in severe earlyonset intrauterine growth restriction. Am J Obstet Gynecol. 2004;190(2):296-304. doi:10.1016/j.ajog.2003.08.011

21. Edwards A, Baker LS, Wallace EM. Changes in fetoplacental vessel flow velocity waveforms following maternal administration of betamethasone. Ultrasound Obstet Gynecol. 2002;20(3):240-244. doi:10.1046/j.1469- 
0705.2002.00782.x

22. Piazze JJ, Anceschi MM, La Torre R, Amici F, Maranghi L, Cosmi EV. Effect of antenatal betamethasone therapy on maternal-fetal Doppler velocimetry. Early Hum Dev. 2001;60(3):225-232.

23. Salama AH, El-Ghetany SM, Hamada AS, Salama DH. Effects of dexamethasone on fetal Doppler flow velocimetry and tests of fetal well-being. Journal of Evidence-Based Women's Health Journal Society. 2013;3(4):186-191. doi:10.1097/01.EBX.0000431017.73252.c9

24. de Kloet ER, Reul JM, Sutanto W. Corticosteroids and the brain. J Steroid Biochem Mol Biol. 1990;37(3):387-394.

25. Chitrit Y, Caubel P, Herrero R, Schwinte AL, Guillaumin D, Boulanger MC. Effects of maternal dexamethasone administration on fetal Doppler flow velocity waveforms. BJOG. 2000;107(4):501-507.
26. Hefny SM, Hashem AM, Yehia AE. Effects of Dexamethasone on Fetal Doppler Indices. Med J Cairo Univ. 2015;83(1):777-779.

27. Senat MV, Ville Y. Effect of steroids on arterial Doppler in intrauterine growth retardation fetuses. Fetal Diagn Ther. 2000;15(1):36-40. doi:10.1159/000020972

28. Barkehall-Thomas A, Thompson M, Baker LS, Edwards A, Wallace EM. Betamethasone associated changes in umbilical artery flow velocity waveforms in multiple pregnancies with umbilical artery absent end diastolic flow. Aust N Z J Obstet Gynaecol. 2003;43(5):360-363.

29. Khazardoost S, Pooransari P, Mirzamoradi M. The effect of betamethasone on fetal movement, biophysical profile and fetal circulation in preterm fetuses. Life Sci J. 2012;9(4):1990-1992.

(c) 2019 The Author (s); This is an open-access article distributed under the terms of the Creative Commons Attribution License (http://creativecommons.org/licenses/by/4.0), which permits unrestricted use, distribution, and reproduction in any medium, provided the original work is properly cited. 